\title{
DESIGN AND TEST OF A MAGNETIC THRUST BEARING
}

\section{N $93=8,37,567$}

P. E. Allaire, Professor (1)

A. Mikula, Director of Marketing (2)

B. Banerjee, Research Associate (1)

D. W. Lewis, Professor (1)

J. Imlach, Research Associate

(1) Mechanical and Aerospace Engineering Department Thornton Hall University of Virginia

Charlottesville, VA

(2) Kingsbury, Inc.

10385 Drummond Road

Philadelphia, PA

\section{ABSTRACT}

A magnetic thrust bearing can be employed to take thrust loads in rotating machinery. This paper describes the design and construction of a prototype magnetic thrust bearing for a high load per weight application. The theory for the bearing is developed in the paper. Fixtures were designed and the bearing was tested for load capacity using a universal testing machine. Various shims were employed to have known gap thicknesses. A comparison of the theory and measured results is presented in the paper.

\section{INTRODUCTION}

Magnetic bearings are beginning to be used in significant numbers of rotating machinery. Industrial uses have included compressors, pumps, and turbines. Uses in space applications may include platform supports, telescopic pointing devices and flywheels. The type of magnetic bearing discussed in this paper is basically a single axis device which might be called either a thrust bearing or a magnetic suspension system.

Normally magnetic bearings for shaft support are employed in a set which includes a double acting thrust bearing and two radial bearings. The thrust bearings have not been discussed in the literature very much, in comparison to radial bearings. The first work by the authors on a magnetic support system of this type was reported in Allaire et al. [1]. This paper describes a single pole electromagnetic support system to verify the concept and compare it to some theoretical calculations. A second paper by Humphris, et al. [2] investigated the effects of control algorithms for magnetic support systems.

Some early work on magnetic thrust bearings was reported by Shimizu and Taniguch $\mathrm{i}[3,4]$. They considered the control system required for operating the bearing. Some information on the S2M design of commercially available thrust bearings is given by Haberman, et al. $[5,6]$ but few details are given. A drawing of a combination radial and thrust bearing is given in [6]. Applications of these bearings have been reported for pipeline compressors by Foster et al. [7] and Hustak 
et al. [8]. Operation of the bearings in the industrial environment has been quite successful.

Work on an unusual magnetic bearing design was reported in $[9,10]$. The bearing was designed to be active axially but passive radially. Lewis and Allaire [11] investigated the potential use of magnetic thrust bearings for control of transmitted forces. The magnetic bearing would be used in conjunction with an oil thrust bearing.

Fairly extensive work has been reported on applications for satellite attitude control and energy storage. A three axis magnetic suspension system is described by Eisenhaure, et al. [12] employing high energy samarium cobalt permanent magnets. Anand, et al. [13] describes a flywheel magnetic bearing of combined active and permanent magnet design.

The purpose of this paper is to discuss the theory associated with active magnetic thrust bearings and present some experimental results on a prototype bearing. The theory describes the properties of the magnetic thrust bearing using electromagnetic principles. Design parameters associated with the bearing are then related to the bearing thrust and effective stiffness and damping parameters. A prototype bearing was constructed and the thrust capability measured. The measured results are compared to the theory.

\section{NOMENCLATURE}

A Area

$A_{1}$ Area of inner pole face

$\mathrm{A}_{2} \quad$ Area of outer pole face

$A_{g} \quad$ Area of air gap

$B$ Magnetic flux density

d Depth of coil gap

$D_{1} \quad$ Inner diameter of stator

$\mathrm{D}_{2} \quad$ Inner diameter of coil gap.

$\mathrm{D}_{3} \quad$ Duter diameter of coil gap

$\mathrm{D}_{4} \quad$ 0uter diameter of stator

F Total force on thrust runner

$F_{p} \quad$ Force on one pole face

$\mathrm{h}$ Effective magnetic circuit gap

$h_{f}$ Effective gap of iron path

$h_{g}$ Air gap i Current in coil

$\mathrm{K}$ Leakage correction factor

L Axial length of stator

$\mathrm{L}_{\mathrm{b}} \quad$ Axial length of stator base

$\mathrm{L}_{\mathrm{f}} \quad$ Length of iron path

$\mathrm{L}_{\mathbf{r}} \quad$ Axial length of thrust runner

$\mathrm{L}_{t} \quad$ Axial length of stator toroids

MMF Magnetomotive force

$\mathrm{N}$ Number of turns in coil

$R$ Total Reluctance of magnetic circuit

$R_{g} \quad$ Reluctance of air gap

$R_{F e}$ Reluctance of iron path

$\mu_{0} \quad$ Permeability of free space (air)

$$
=4 \pi \times 10^{-7} \mathrm{~Wb} / \mathrm{A} \text { - turn-m }
$$

$\mu_{\mathrm{r}} \quad$ Relative permeability of iron (4000)

$\phi \quad$ Magnet ic flux

\section{MAGNETIC THRUST BEARING DESCRIPTION}

A magnetic thrust bearing has an electromagnetic stator and a thrust runner, as illustrated in Fig. 1. They are separated by an air gap or water gap when applied to 
a pump. Because the electromagnet is attractive, the thrust bearing must be double acting to operate successfully for most applications. This is discussed in more detail later in the paper.

In its simplest form, the electromagnetic stator is formed by an inner and outer toroid connected by a common base. Figure 2 shows an exploded view of the stator, shaft, and thrust collar of a single acting bearing. All of the magnetic components are made of magnet iron. The inner and outer toroids and base may be constructed of separate pieces for ease of assembly. They may be held together by screws or other methods. Figure 3 gives a perspective view of the assembled stator. A coil of wire occupies the space between the inner and outer toroids. This produces the magnetic flux in the bearing. Magnetic flux paths are illustrated in Fig. 4 flowing through the inner and outer toroids as well as the thrust runner. It is important to provide a good flux path to avoid leakage from the magnetic components.

The rotating part of the bearing, in its simplest form, is a solid disk made of magnet iron and attached to the shaft. Fig. 2 illustrates this construction of the thrust runner. Unlike the rotating part of radial magnetic bearings, the thrust runner does not cross alternating magnetic flux lines so it does not have to be laminated to reduce eddy currents.

An electronic circuit controls the current in the coils of the stator, as illustrated in Fig. 4. The axial position of the thrust runner is continuously. monitored by a sensor. The voltage from the sensor is fed into a sensor amplifier. This in turn enters a compensator, summer, and lead network or other network suitable for a given application. A current amplifier then supplies the appropriate current to the coils in the magnetic stator.

A steady state current provides the attractive force between the stator and runner which gives the bearing its steady load capacity. The bearing by itself has a negative stiffness (discussed later in [2]) so an automatic control circuit is required to give the bearing an effective positive stiffness. The position sensor is used to sense the axial position of the shaft and to provide the feedback signal to the control loop which creates the positive stiffness.

\section{THEORETICAL MODEL}

The theoretical model of the thrust bearing used in this paper is a one dimensional theory. It is assumed that the flux can be taken as varying only along the flux lines. No attempt is made here to do a finite element analysis of the magnetic flux in a two or three dimensional manner.

Several assumptions are made in this derivation for the sake of simplicity:

1. No leakage occurs between the toroids.

2. Flux levels are always below saturation.

3. Changes in the current are small compared to the steady state level.

4. Axial shaft motions are small compared to the steady state air gap.

5. A one dimensional model of the magnetic path may be used.

The first assumption is valid if the radial dimension of the space between the toroids is large compared to the air gap. If not, a leakage factor can be used as developed in Appendix A. The second assumption depends upon the proper design of the thrust bearing for the expected loads. Both assumptions 3 and 4 are generally valid 
if the bearing is operating properly. The steady state current is usually large compared to oscillating thrust loads and the axial motions are small relative to the large magnetic bearing gap thickness. Finally, a one dimensional model of the magnet ic path provides a reasonable first approximation .

All of the above assumptions may be violated to some extent by actual magnetic thrust bearings and probably are. However, that means that more complex analys is needs to be carried out to supplement the analysis given here. This approach can be used for preliminary design purposes.

\section{MAGNETIC CIRCUTT RELUCTANCE}

The pole face areas $A_{1}$ and $A_{2}$ are given by (see Figure 5)

$$
\begin{aligned}
& A_{1}=\frac{\pi}{4}\left(D_{2}{ }^{2}-D_{1}{ }^{2}\right) \\
& A_{2}=\frac{\pi}{4}\left(D_{4}{ }^{2}-D_{3}{ }^{2}\right)
\end{aligned}
$$

These areas are made equal so that the magnetic flux has the same level in each torroid. The pole face area then equals the air gap area Ag. Also, the location of the most restrictive area in the stator base is the perimeter at the outer diameter of the inner toroid. Thus the length of the base is given by

$$
\mathrm{L}_{\mathrm{b}}=\mathrm{L}-\mathrm{L}_{\mathrm{t}}=\frac{\mathrm{A}_{\mathrm{g}}}{\pi \mathrm{D}_{2}}
$$

The thrust runner has thickness $L_{r}$ equal to this value.

The reluctance of each air gap is given by

$$
\mathrm{R}_{\mathrm{g}}=\frac{\mathrm{h}_{\mathrm{g}}}{\mu_{\mathrm{o}} \mathrm{A}_{\mathrm{g}}}
$$

and the reluctance of the iron path is

$$
\mathrm{R}_{\mathrm{f}}=\frac{\mathrm{L}_{\mathrm{f}}}{\mu_{\mathrm{o}} \mu_{\mathrm{r}} A_{\mathrm{g}}}
$$

Let the length of air gap magnetically be equal to the iron path $h_{f}$ with value

$$
\mathrm{h}_{\mathrm{f}}=\frac{\mathrm{L}_{\mathrm{f}}}{\mu_{\mathrm{r}}}
$$

The total reluctance of the magnetic circuit is

$$
R=2 R_{g}+R_{f}=\frac{1}{\mu_{0} A_{g}}\left[2 h_{g}+h_{f}\right]
$$

Thus the effective magnetic gap is $h$ where

$$
h=2 h_{g}+h_{f}
$$

including both air gaps and the iron path. 


\section{MAGNETIC FLUX}

A magnetomotive force (MMF) is equal to the number of turns in the coil times the current

$$
\text { MMF }=\mathrm{Ni}
$$

The magnetic flux is then found from

$$
\phi=\frac{M M F}{R}=\frac{\mu_{0} A_{\mathrm{gi}}}{h}
$$

and the flux density is

$$
B=\frac{\phi}{A_{g}}=\frac{\mu_{0} \mathrm{Ni}}{h}
$$

This must not exceed the saturation level for the particular magnetic material involved. Typical values for silicon iron are 1.2 to 1.6 tesla and for rare earth materials up to 2.0 tesla.

Often the steady state (also called bias flux level) is chosen as one half of the saturation flux level. This value gets the operating point of the thrust bearing up in the linear range of the flux but still leaves operating room for increased flux for higher load capacity as needed.

\section{LOAD CAPACITY}

Each pole face develops an attractive force with value

$$
\mathrm{F}_{\mathrm{p}}=\frac{\phi^{2}}{2 \mu \mathrm{A}}=\frac{\mu_{\mathrm{o}} \mathrm{A}_{\mathrm{g}} \mathrm{N}^{2} \mathrm{i}^{2}}{2 \mathrm{~h}^{2}}
$$

There are two pole faces so the total force is

$$
\mathrm{F}=2 \mathrm{~F} p=\frac{\mu_{0} \mathrm{~A}_{\mathrm{g}} \mathrm{N}^{2} \mathrm{i}^{2}}{\mathrm{~h}^{2}}
$$

The actual force is somewhat reduced by leakage effects. A leakage parameter $\mathrm{k}$ is calculated for the thrust bearing geometry. The thrust bearing load capacity is then modified to include $k$ as

$$
\mathrm{F}=\frac{\mu_{0} \mathrm{~A}_{\mathrm{g}} \mathrm{N}^{2} \mathrm{i}^{2}}{\mathrm{k}^{2} \mathrm{~h}^{2}}
$$

Appendix A gives the calculation method for $k$.

In most industrial applications, the thrust bearing must be made double acting. Figure 6 illustrates the geometry when a single thrust runner is employed in a double acting bearing. 0ther rotating machines employ a split double acting thrust bearing. An example is a canned motor pump with one thrust bearing at the pump end of the canned motor and the other thrust bearing at the opposite end of the motor. The load capacity (force acting on the thrust runner) of the double acting thrust bearing is

$$
F=\left[\frac{\mu_{0} \mathrm{~A}^{\mathrm{N}} \mathrm{N}^{2}}{\mathrm{k}^{2} \mathrm{~h}^{2}}\right]_{2}-\left[\frac{\mu_{0} \mathrm{~A}_{\mathrm{h}} \mathrm{N}^{2}}{\mathrm{kh}^{2}}\right]_{1}
$$

where 1 denotes the left side and 2 denotes the right side. Clearly, if the two sides are identical the thrust load is zero. However, as a thrust load is applied, 
the runner will move in the axial direction creating a difference in air gaps. The automatic control circuit insures that this thrust bearing will have positive effective stiffness and damping dynamic coefficients.

\section{PROTOTYPE THRUST BEARING}

A prototype single acting thrust bearing was constructed for load capacity testing. Figure 7 shows the assembled thrust bearing but without a thrust runner (which would be attached to a shaft). Figure 8 presents the prototype bearing disassembled. Also shown is the thrust runner on the left side of the photograph. The lead wires for the coil come out of holes in the stator base for connection to the control circuit.

\begin{tabular}{|c|c|}
\hline $\begin{array}{l}\text { Axial length } \\
\text { Inner diameter of stator }\end{array}$ & $\begin{array}{l}\mathrm{L}=50.800 \mathrm{~mm}(2.00 \mathrm{in}) \\
\mathrm{D}_{1}=40.945 \mathrm{~mm}(1.612 \mathrm{in})\end{array}$ \\
\hline Inner diameter of coil gap & $\mathrm{D}_{2}=64.414 \mathrm{~mm}(2.536 \mathrm{in})$ \\
\hline Outer diameter of coil gap & $\mathrm{D}_{3}=71.272 \mathrm{~mm}(2.806 \mathrm{in})$ \\
\hline Outer diameter of stator & $\mathrm{D}_{4}=93.345 \mathrm{~mm}(3.675 \mathrm{in})$ \\
\hline $\begin{array}{l}\text { Depth of coil gap } \\
\text { Axial length of thrust runner }\end{array}$ & $\begin{array}{l}\mathrm{d}=39.116 \mathrm{~mm}(1.54 \mathrm{in}) \\
\mathrm{L}_{\mathrm{r}}=10.160 \mathrm{~mm}(0.40 \mathrm{in})\end{array}$ \\
\hline Air gap & $\mathrm{h}_{\mathrm{g}}=0.508 \mathrm{~mm}(20 \mathrm{mils})$ \\
\hline
\end{tabular}

\section{LOAD CAPACITY TESTING}

It was desired to measure the load capacity of the thrust bearing for comparison to the calculated values. A standard tensile testing device was used to apply loads to the bearing. First, the stator was mounted on a test base as shown in Figure 9. Second, a thin nonmagnetic shim was placed on top of the stator. Third, the thrust runner was attached to the movable part of the tensile tester. The assembled test setup is illustrated in Fig. 10. The prototype thrust bearing is shown in the bottom of the photograph. Immediately above the thrust bearing is a load equalizing device to avoid cocking of loads higher on one side than the other. At the top of the photograph is the load cell used to measure the bearing load capacity.

Testing was accomplished by turning on the current in the coil and applying a load to the tester. The gap thickness is known because of the nonmagnetic shim in the normal air gap region of the bearing. The permeability of the aluminum shim is essentially the same as that of air so the effect is that of having air in the gap. Two shims were used: $0.37 \mathrm{~mm}(14.5 \mathrm{mils})$ and $0.50 \mathrm{~mm}(19.5 \mathrm{mils})$. The current in the coil is increased and the thrust load capacity measured.

A number of difficulties were encountered with using the tensile tester. Basically, it is designed as a materials test device. It proved impossible to construct a bearing holder which had zero axial tolerances. With the clearances of the testing machine and those of the magnetic bearing test device, there was always a certain amount of initial force takeup before the steady state load was attained on the thrust bearing and actual test data was taken. In short, this procedure did not produce good, reproducible test results. 
Another type of test, called the drop test, was performed on the thrust bearing. In this test, a known dead load is brought up to a specific distance (separation) to the face of the thrust bearing. This separation is determined by the particular aluminum shim used for the test. Current is then applied to the bearing of sufficient level such that the dead load is captured. The dead load and the bearing is raised by the universal testing machine so that the bearing alone is carrying the dead load. Then the current level to the bearing is slowly reduced to the point at which the bearing can no longer support the load. The dead load then drops from the bearing. The current level at this point is recorded with the value of the dead load and this yields one point on the LOAD vs CURRENT curve for the particular shim (or equivalent air gap of the bearing).

Figure 11 gives the results for the measured load capacity with $0.37 \mathrm{~mm}(14.5$ mils): Figure 12 shows similar results with a $0.50 \mathrm{~mm}(19.5 \mathrm{mil})$ shim. The theory used is one dimensional and considers unrolling the toroids and not producing sufficiently accurate leakage factor for this geometry. More consideration needs to be done to generate more precise leakage factors.

For a significant range (close to our operating range) the slope of the simplified theory curve agrees fairly well with the experimental work (drop test). The theory is of proper sign in that there are losses that have not been considered so when further delineation of the flux leakage is produced, the theoretical curve will be shifted to the right and the slope will decrease.

The theory for the larger gap (clearance) understates the current by some 18 percent which is sufficient for design purposes because the sign of the error is known. The design conditions for this bearing called for a $0.508 \mathrm{~mm}(\simeq 20 \mathrm{mi} 1)$ gap. This prototype bearing was designed to carry a maximum load of $136 \mathrm{~kg}$ (300 1bs) at 0.9 amps. A redesign has been made with the new design handling up to 1.8 amp and with capacity to handle the maximum load.

\section{INDUSTRIAL APPLICATION}

The above theory was employed to design and construct a double acting magnetic thrust bearing for a canned motor pump. The pump has a single stage overhung centrifugal impeller and the canned motor is centrally mounted between the bearings. Figure 13 is a photograph of the pump. Both radial and thrust bearings were originally made of carbon. Unfortunately these bearings have relatively short operating life, less than one year, in hydrocarbon and other service. The objective of replacing the original product-lubricated bearings with magnetic bearings is to produce an extension of 1 ife. The objective is five years. As yet there is no data available on the extremely few applications of magnetic bearings to pumps. It is the authors ' understanding that magnetic bearings have been installed in a vertical pump for the French Navy but that no results have been made public.

The thrust bearing is split for this canned pump so that one side is between the impeller and motor and the other side is outboard of the motor. The magnetic bearings have the same configuration. They $\mathrm{fit}$ in the same components that the original bearings do except for modified bearing housings at both ends. All other components such as the impeller, casing, motor, and shaft have not been replaced or substantially modified. Actually, the radial bearings are being replaced also but this paper is concerned with thrust bearings. 
The status of this project at this point in time, January 1988, is that the bearings have been designed and are being constructed. Construction will be completed and testing done over the spring of 1988. A complete pump test loop has been constructed for this purpose. Full operational flow and vibration measurements were made on the pump with the original bearings before any modifications were made. These will serve as the benchmark measurements.

\section{CONCLUSIONS}

This paper describes the theoretical modeling of a magnetic thrust bearing. The theory is a one dimensional model of the magnetic flux path through the bearing and resulting forces acting on the thrust runner. Some simplified leakage effects were included in the model. No attempt has been made to develop a more accurate two or three dimensional finite element model of the bearing as yet.

A single acting prototype was designed with this theory and tested for load capacity. The theory over-predicted the load capacity by a significant fraction but did give a good feel for the trends in the bearing. Some problems were encountered with the initial testing which probably resulted in some measurement errors. The drop testing procedure has produced more reliable and repeatable results so that the relatively simple theory employed gives a good starting place for design purposes.

Bearings of this type have been designed for a canned motor pump. They are currently being constructed and will be tested in the pump in the near future.

\section{ACKNOWLEDGMENTS}

This work was funded in part by Kingsbury, Inc. and the Center for Innovative Technology of the Commonwealth of Virginia.

\section{REFERENCES}

1. Allaire, P. E., Humphris, R. R., and Kelm, R. D., "Magnetic Bearings For Vibration Reduction and Failure Prevention," Mechanical Failures Prevention Group, 40th Meeting, April 16-18, National Bureau of Standards, Gaithersburg, Maryland.

2. Humphris, R. R., Kelm, R. D., Lewis, D. W., and Allaire, P. E., "Effect of Control Algorithms on Magnetic Journal Bearing Properties," Journal of Engineering for Gas Turbines and Power, Trans. ASME, Vol. 108, October 1986, pp. 624-632.

3. Shimizu, H. and Taniguchi, 0., "Research on the Control Systems of Magnetic Bearing," Bulletin of J. S. M. E., Vol. 11, No. 46, 1968, pp. 699-705.

4. Shimizu, H. and Taniguchi, 0., "Research on the Self-Exciting Vibration of Thrust-Type Magnetic Bearing (Cylindrical Mode), "Bulletin of J. S. M. E., Vol. 14, No. 72,1971 , pp. 541-549.

5. Haberman, H. and Liard, G., "An Active Magnetic Bearing System," Tribology International, April 1980, pp. 85-89. 
6. Haberman, H. and Brunet, M., "The Active Magnetic Bearing Enables Optimum Damping of Flexible Rotor," ASME Paper No. 84-GT-117, ASME Gas Turbine Conference, Amsterdam, June 1984.

7. Foster, E. G., Kulle, V., and Peterson, R. A., "The Application of Active Magnetic Bearings to a Natural Gas Pipeline Compressor, "ASME Paper 86- GT-61, Presented at International Gas Turbine Conference, Dusseldorf, June 8-12, 1986.

8. Hustak, J. F., Kirk, R. G., and Schoeneck, K. A., "Analysis and Test Results of Turbocompressors Using Active Magnetic Bearings," American Society of Lubrication Engineers, Preprint No. 86- AM-1A-1, Presented at 41st Annual Meeting, Toronto, May $12-15,1986$.

9. Walowit, J. A. and Pinkus, 0., "Analytical and Experimental Investigation of Magnetic Support Systems. Part I: Analysis," Journal of Lubrication Technology, Trans. ASME, Vol. 104, No. 3, July 1982, pp. 418-428.

10. Albrecht, P. R., Walowit, J. A., and Pinkus, 0., "Analytical and Experimental Investigation of Magnetic Support Systems. Part II: Experimental Investigation," Journal of Lubrication Technology, Trans. ASME, Vol. 104, No. 3, July 1982, pp. 429-437.

11. Lewis, D. W., and Allaire, P. E., "Control of 0scillating Transmitted Forces in Axial Thrust Bearings with a Secondary Magnetic Bearing," ASLE Transactions, Vol. 30, No. 1, January 1987, pp. 1-10.

12. Eisenhaure, D. B., Downer, J. R., Bliamptis, T. E., and Ilendrie, S. D., "A Combined Attitude, Reference and Energy Storage System for Satellite Applications," AIAA Aerospace Sciences Mecting, Reno, Nevada, January 9-12, 1984.

13. Anand, D. K., Kirk, J. A., and Bangham, M. L., "Simulation, Design and Construction of a Flywheel Magnetic Bearing," Design Engineering Technical Conference, ASME, Columbus, 0hio, October 5-8, 1986.

\section{APPENDIX A}

\section{A.1 Introduction}

The flux path that has been assumed is not the only one for the magnetic thrust bearing, even though it is the only effective one for our needs. There are a number of other flux paths across the air gap which are traversed by leakage flux. This reduces the thrust capability of the bearing, since a part of the magnetomotive force is wasted to sustain the leakage flux.

\section{A.2 Calculation of Permeances}

Before the leakage coefficient can be calculated, it is necessary to compute the permeance of all the significant flux paths in the air gap. A quite comprehensive analysis for the estimation of these permeances has been presented by Roters [12]. The following material is based on his treatment of the matter.

Figure 14 identifies by number the various flux paths in the air gap that are being considered here. The two basic formulae that we need are those for the permeance of a magnetic field between parallel plane surfaces of infinite extent, and 
that of a magnetic field between non-parallel plane surfaces of infinite extent. For the former, with reference to Figure 15 , the permeance $\Lambda$ is given by

where

$$
\Lambda=\mu \frac{S}{l}
$$

$S$ is the surface area of each of the two plane surfaces,

$l$ is the length of the gap between the surfaces,

$\mu$ is the permeability of the medium separating the surfaces.

For a pair of non-parallel surfaces, as shown in Figure 16, a cylindrical shell of flux of radial thickness $d r$ and axial length $l$ may be considered. Application of equation (A.2.1) and subsequent integration over $d r$ gives us

where

$$
\Lambda=\frac{\mu l}{\theta} \ln \frac{r_{2}}{r_{1}}
$$

$l, \theta, r_{2}$, and $r_{1}$ are as shown in Figure 16.

The permeances of the four flux paths of interest can now be determined.

Path 1: Equation (A.2.2) can be used, with

to give us

$$
l=\pi D_{4}, \theta=\pi, r_{1}=h_{g} / 2 \text {, and } r_{2}=\mathrm{L}_{\mathrm{r}}+h_{g} / 2
$$

$$
\Lambda_{1}=\mu_{0} D_{4} \ln \left[1+2 \mathrm{~L}_{\mathrm{r}} / h_{g}\right]
$$

where

$D_{4}$ is the outer diameter of the bearing,

$\mathrm{L}_{\mathrm{r}}$ is the thickness of the thrust collar, and

$h_{g}$ is the air gap between the bearing and the collar.

Path 2: This flux path is a semicircular cylindrical volume. The mean length of the path is that of a line drawn midway between the diameter and the circumference of the semicircle. This equals $1.22 \mathrm{~h}$ by graphical measurement. The mean area of the flux path is estimated by dividing the volume of the path by this mean length. On applying equation (A.2.1) now, we get

$$
\Lambda_{2}=\frac{\mu_{0}}{1.22 h_{g}} \frac{\pi h_{g}^{2}\left(\pi D_{4}\right)}{8 \times 1.22 h_{g}}=0.26 \pi \mu_{0} D_{1}
$$

Path 4: This path has twice the length of path 2 and is identical to it in every other respect, so that it has twice the permeance:

$$
\Lambda_{4}=0.52 \pi \mu_{0} D_{3}
$$


Path 3: This is the only path for the useful flux. Equation (A.2.1) can be used with $S=\pi\left[D_{4}^{2}-D_{3}^{2}\right] / 4$ and $l=h_{g}$, to give us

$$
\Lambda_{3}=\frac{\pi \mu_{0}}{4} \frac{D_{4}^{2}-D_{3}^{2}}{h_{g}}
$$

where

$D_{3}$ is the inner diameter of the outer pole.

\section{A.3 The Leakage Factor}

The ratio of the total gap permeance to the useful gap permeance is defined as the leakage factor. Thus, for the outer pole of the magnetic thrust bearing, we have

$$
k_{\text {outer }}=\frac{\Lambda_{1}+\Lambda_{2}+\Lambda_{3}+\Lambda_{4}}{\Lambda_{3}}
$$

The leakage factor for the inner pole, $\stackrel{3}{k}_{i n n e r}$, can be found in the same way, with $D_{4}, D_{3}$ replaced respectively by $D_{1}, D_{2}$. The higher of these two values is chosen as the effective leakage factor, since the useful flux at one of the two poles is determined by this, and the flux intersecting each of the two pole faces is assumed to be the same. Therefore, in equation (10), $\phi$ must be divided by the effective leakage factor $k$. Since the force developed is proportional to the square of the flux, this means that the right hand side of equation (13) must be divided by the square of $k$ to get the effective value of thrust capacity. This is what has been done in equation (14).

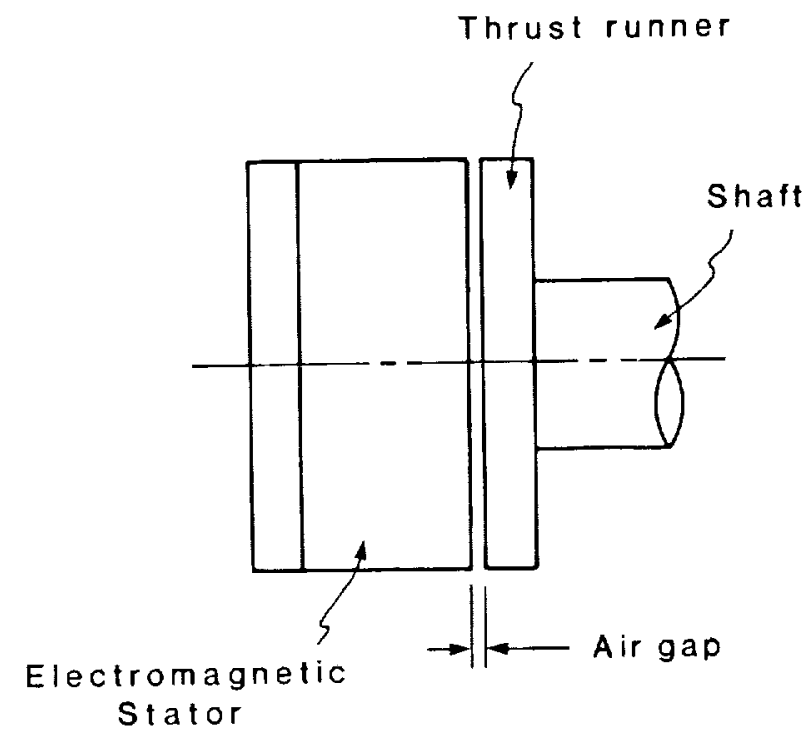

Figure 1. Basic Magnetic Thrust Bearing Geometry 


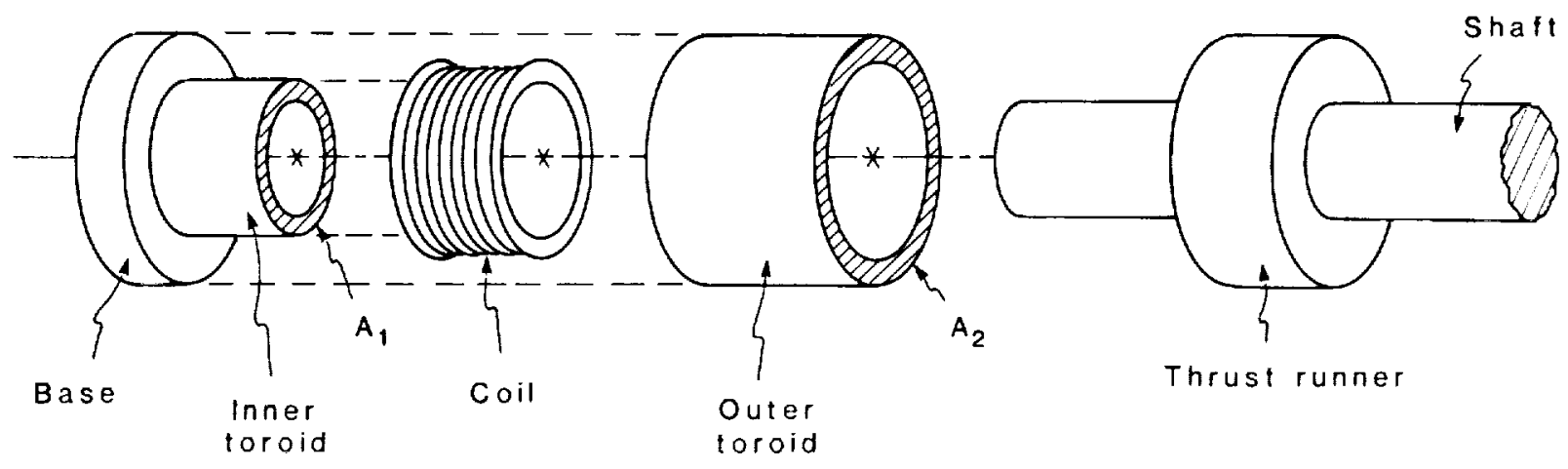

Figure 2. Exploded View of Single Acting Magnetic Thrust Bearing

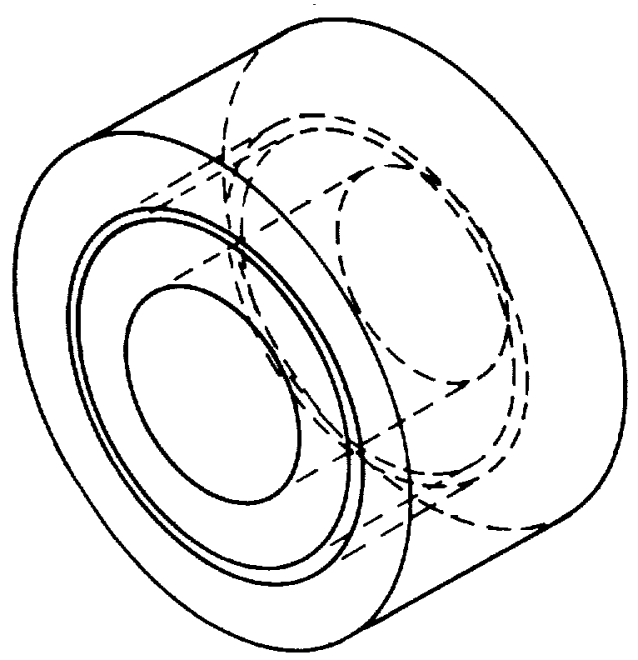

Figure 3. Perspective View of Stator for Magnetic

Thrust Bearing 


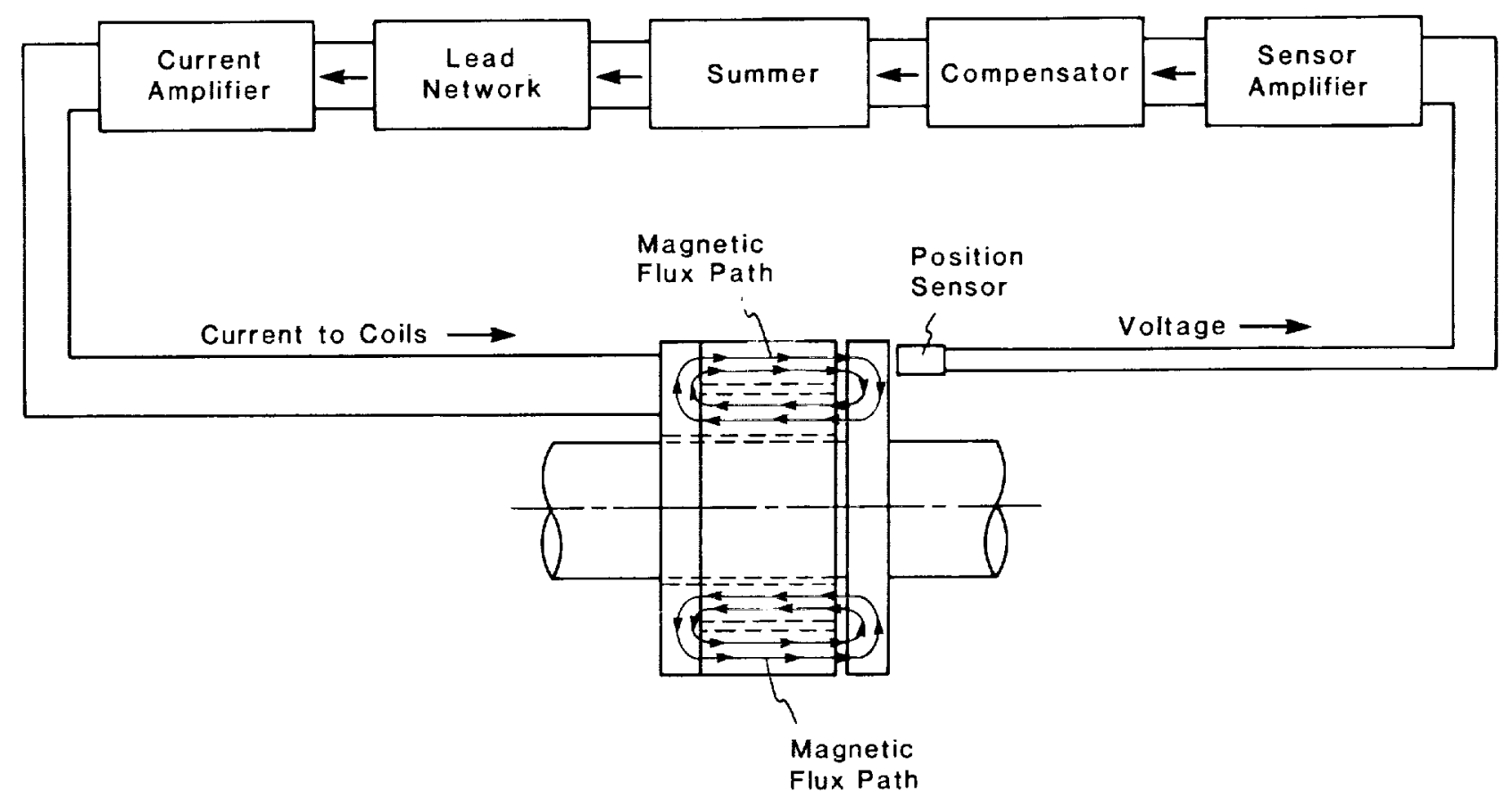

Figure 4. Magnetic Flux $P$ aths and Control Loop in Single Acting Magnetic Thrust Bearing

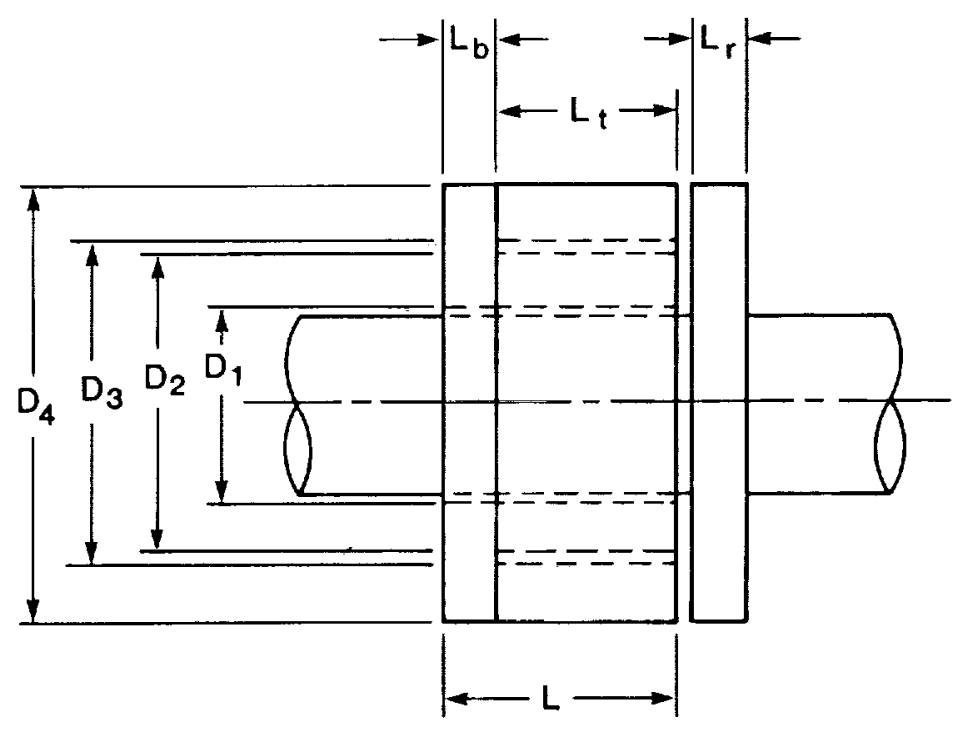

Figure 5. Geometry of Single Acting Magnetic Thrust Bearing 


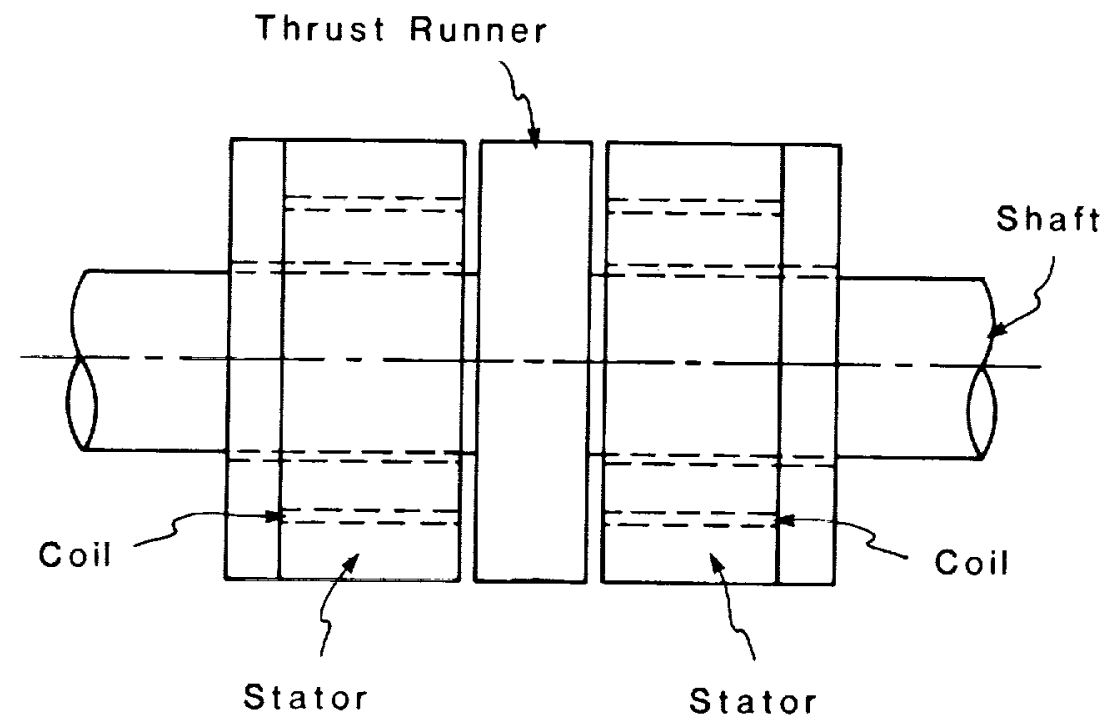

Figure 6. Geometry of Double Acting Thrust Bearing

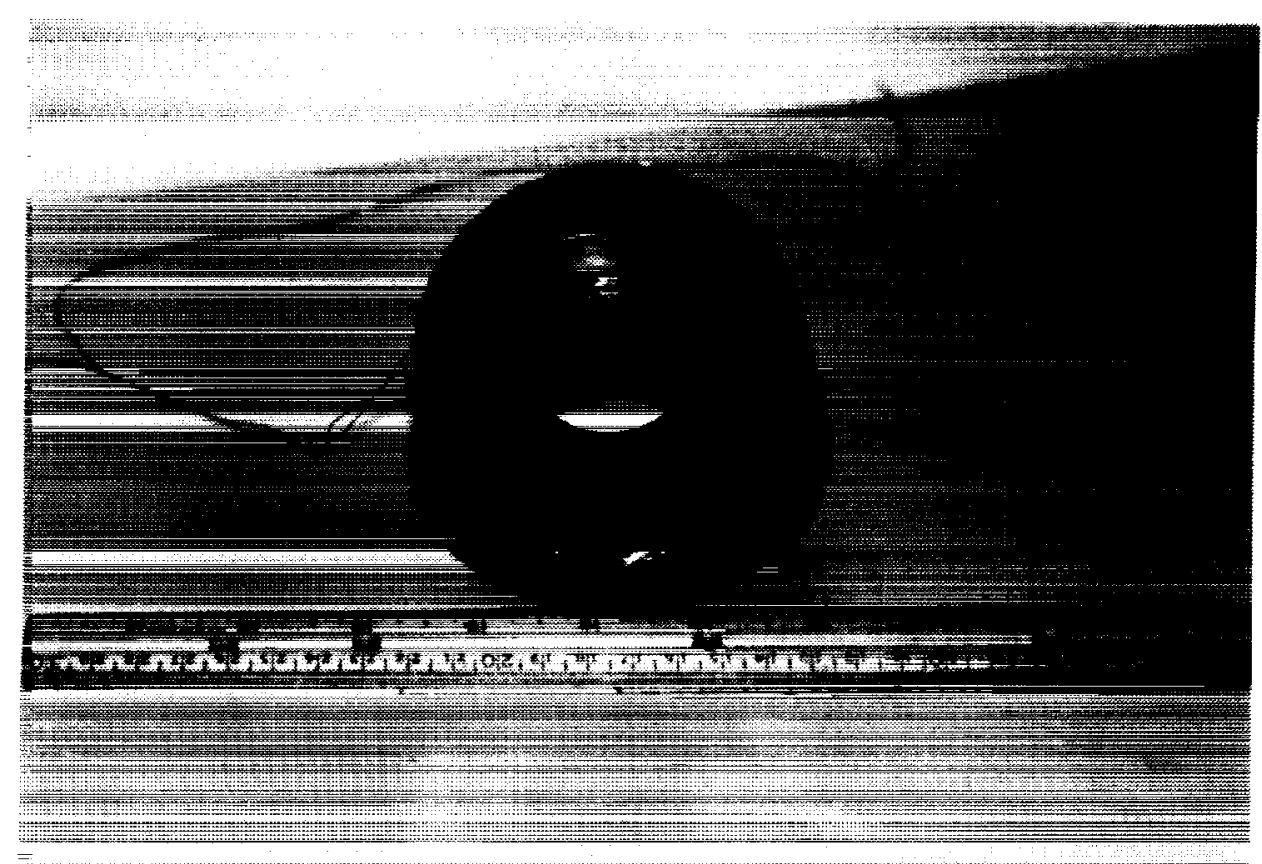

Figure 7. Prototype Thrust Bearing 


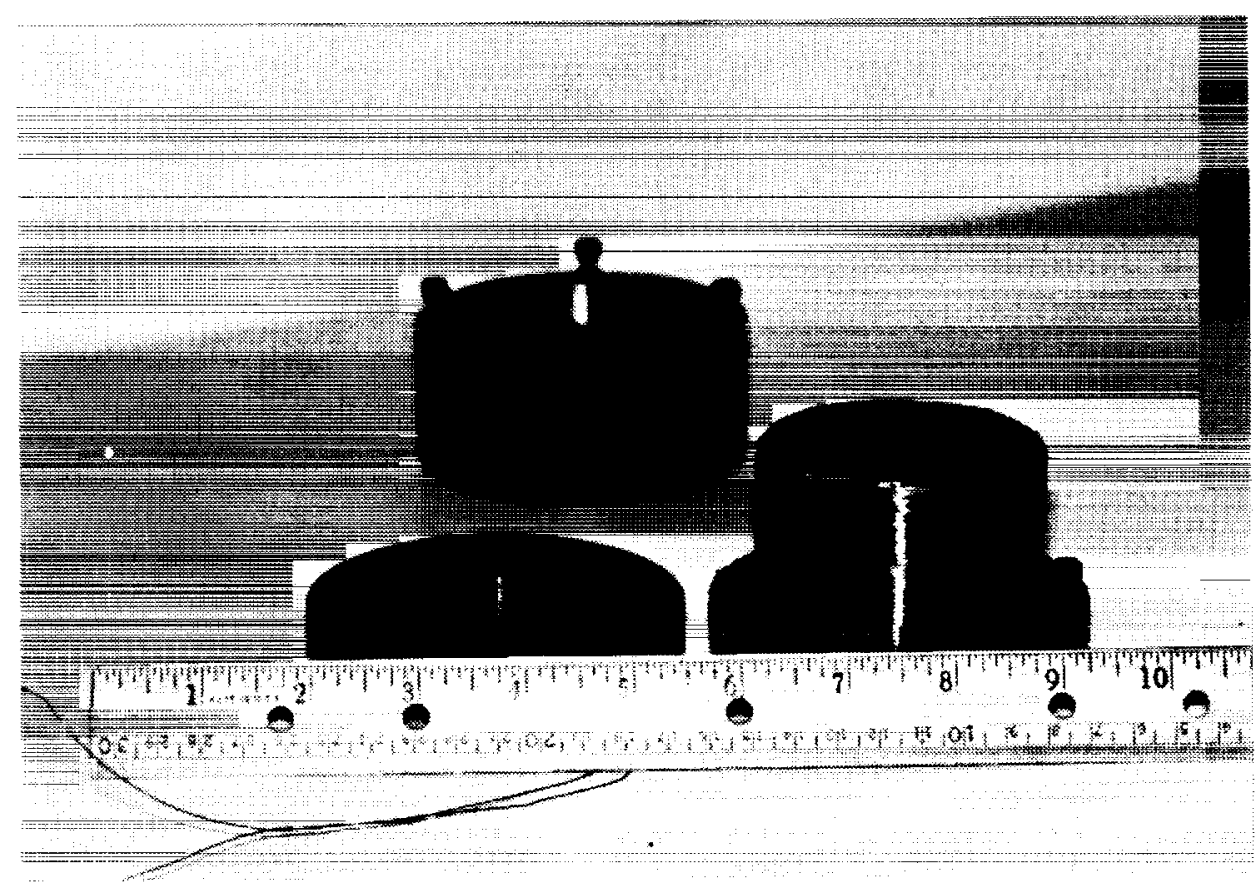

Figure 8. Disassembled Thrust Bearing

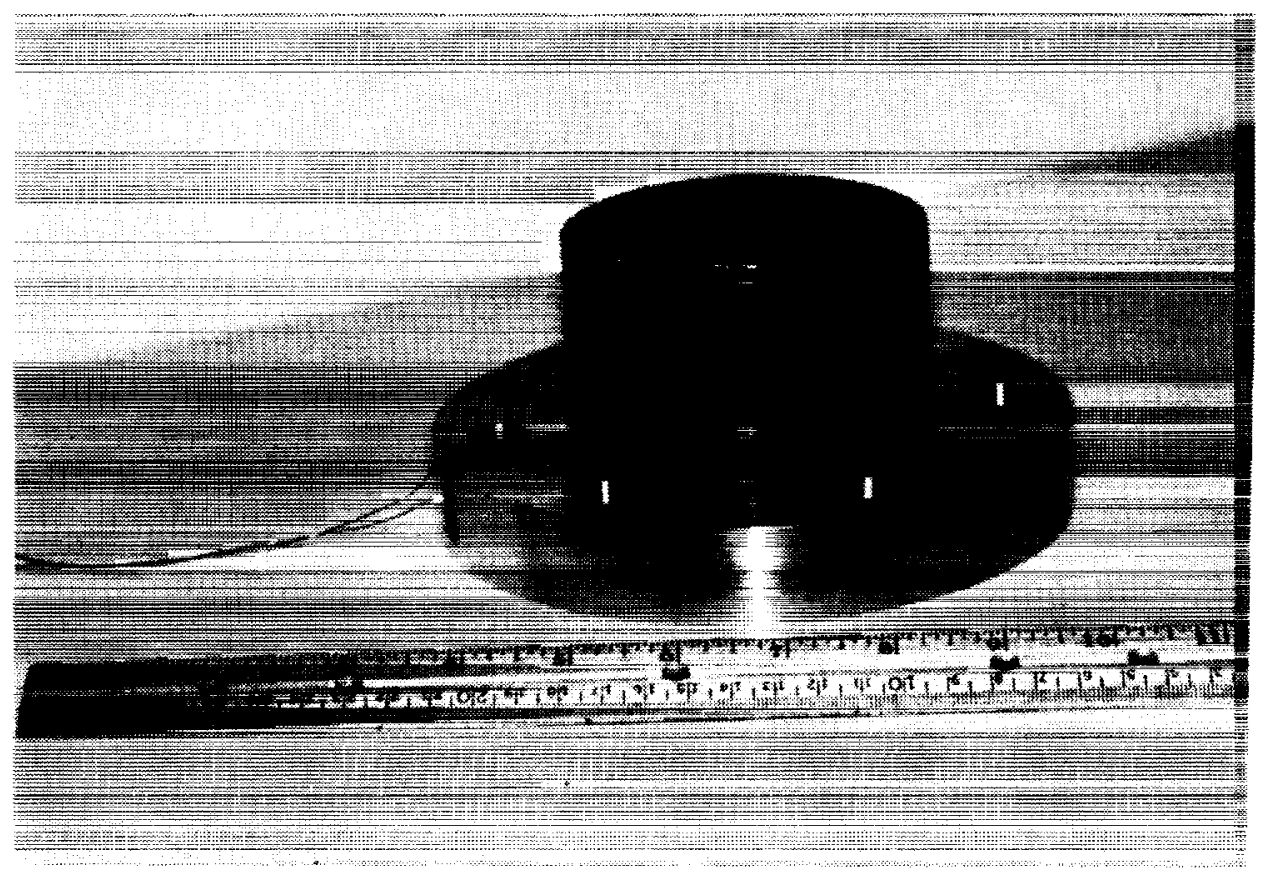
Figure 9. Thrust Bearing Mounted on Test Base

OR!GINAL PAGE

BLACK AND WHITE PHOTGGRAPH 


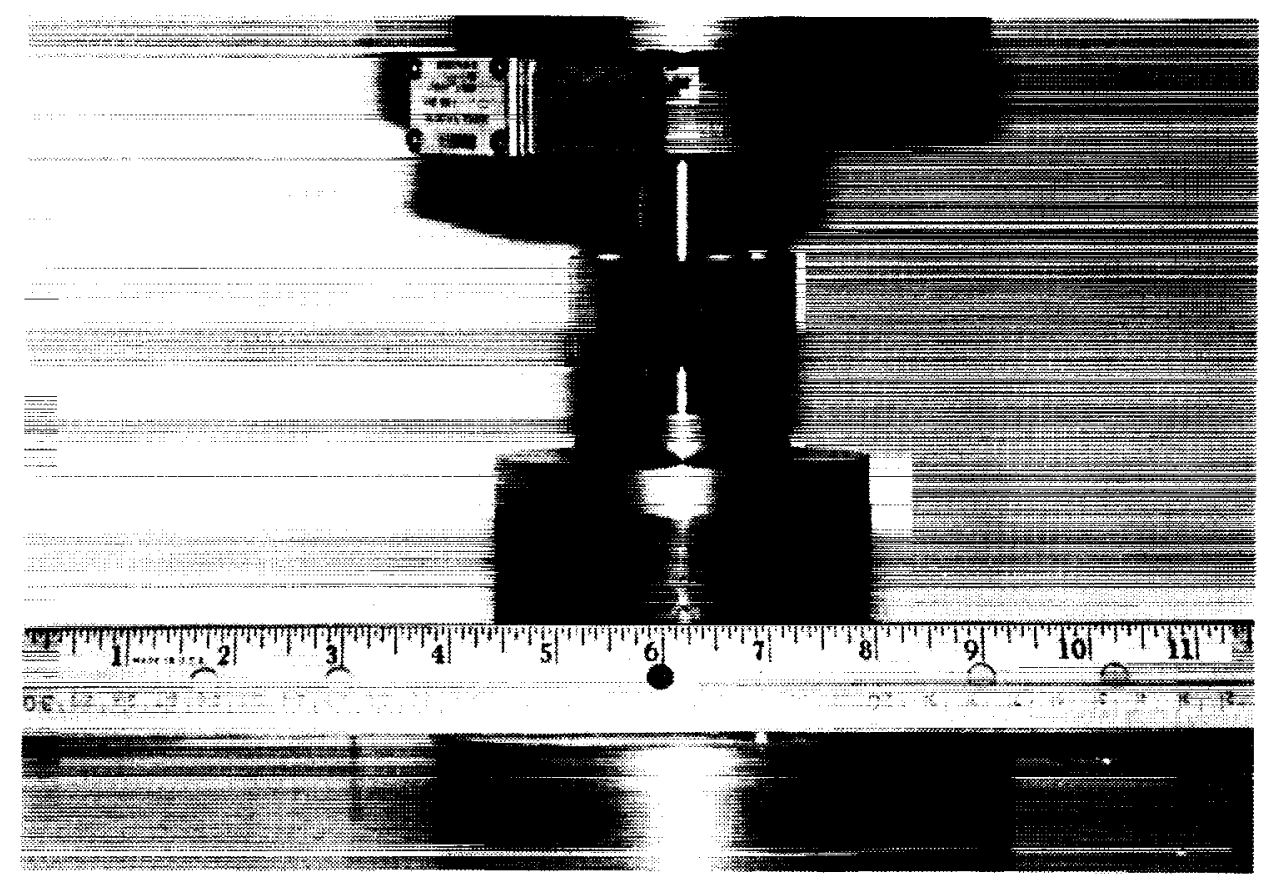

Figure 10. Thrust Bearing in Tensile Test Device

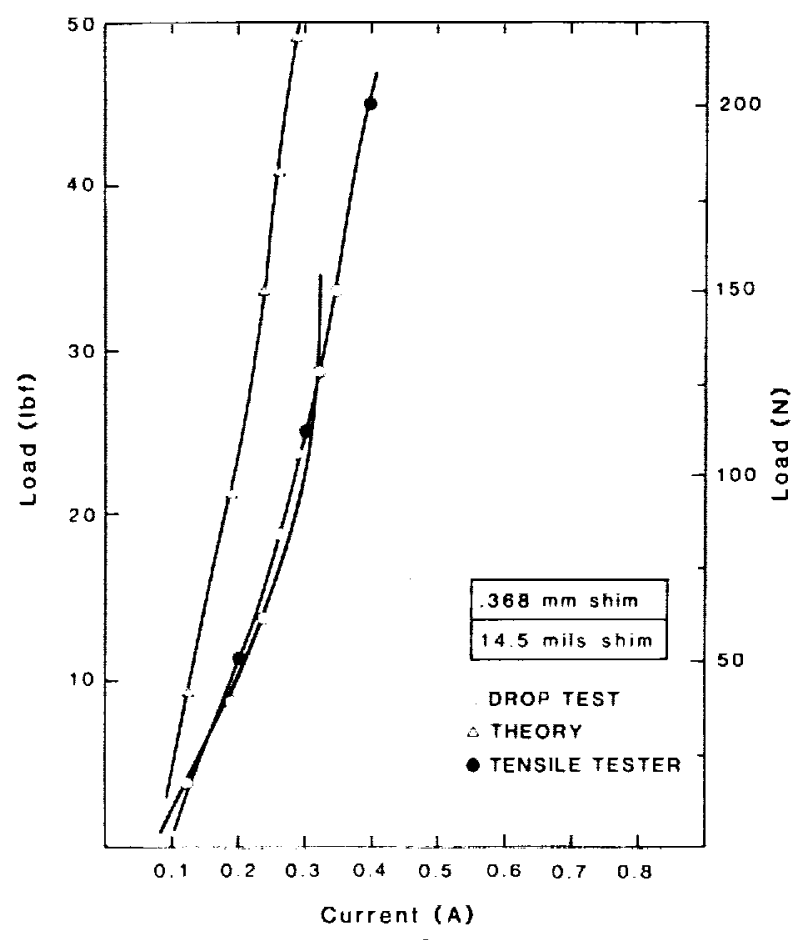

Figure 11. Thrust Force vs. Current for Magnetic Thrust Bearing with Gap Thickness of 14.5 mils. 


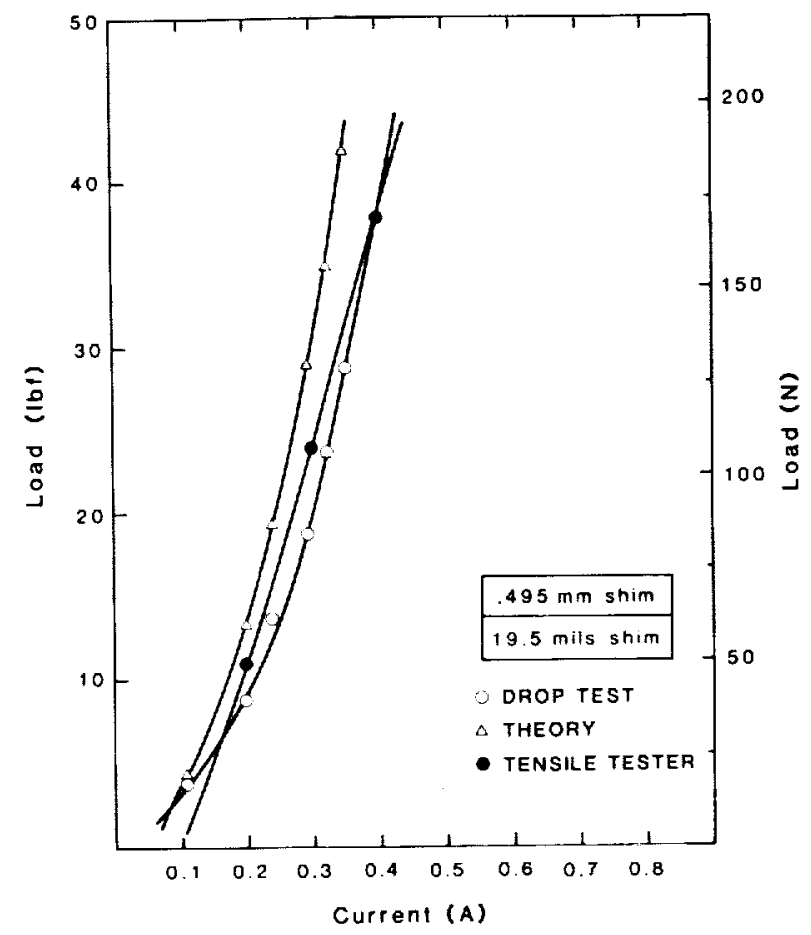

Figure 12. Thrust Force vs. Current for Magnetic Thrust Bearing with Gap Thickness of 19.5 mils.

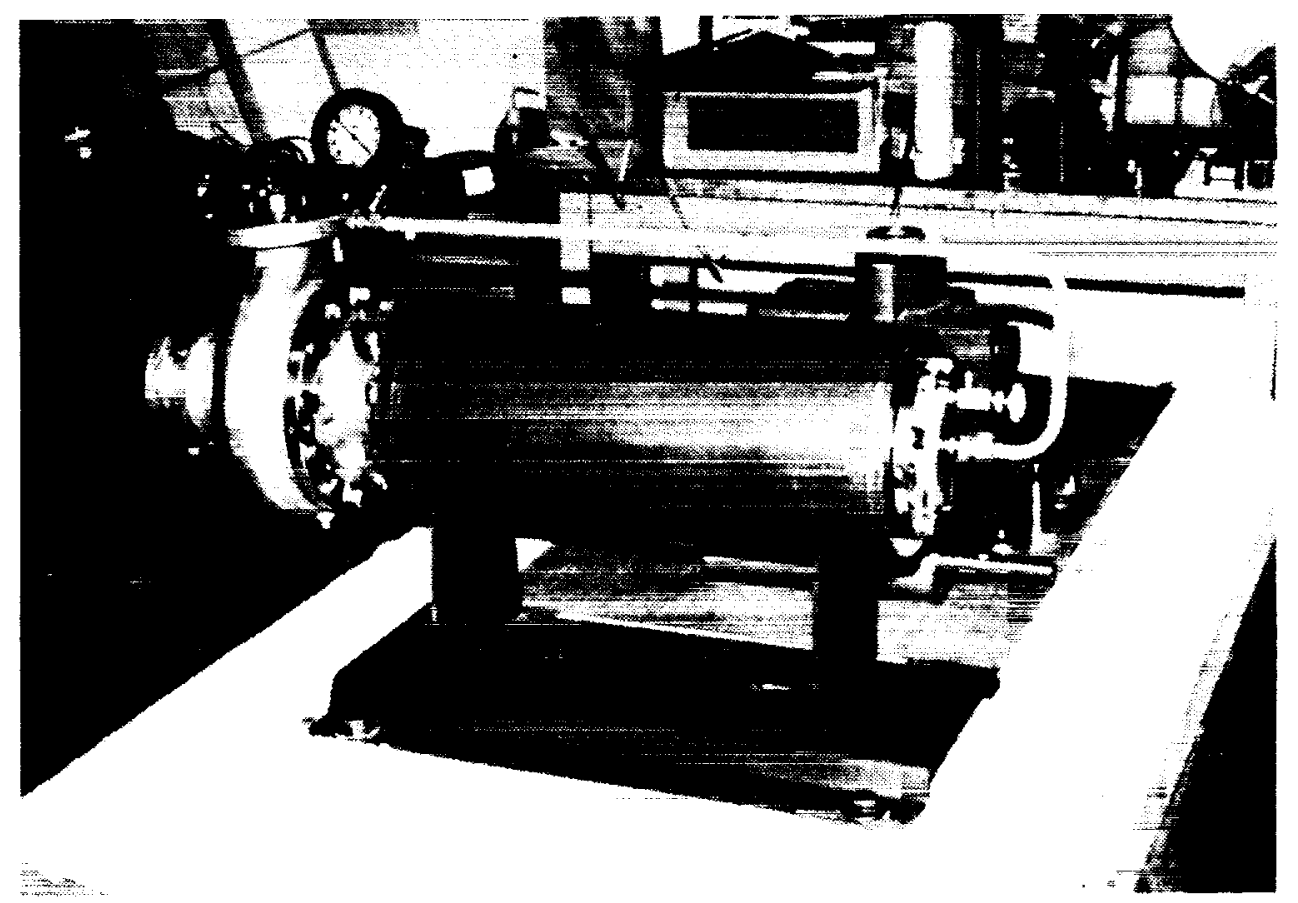

Figure 13. Canned Motor Pump Being Converted to Magnetic Bearings 


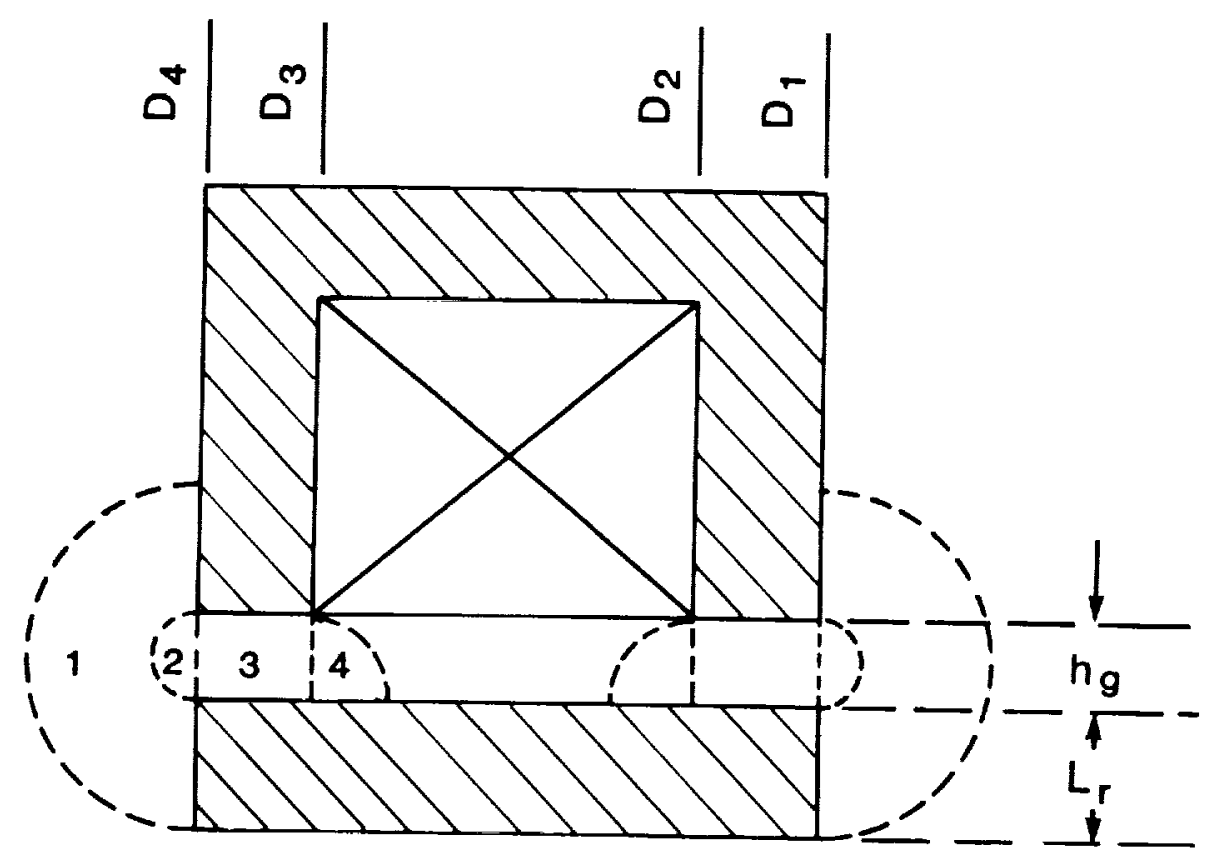

Figure 14. Section of Thrust Bearing System Showing Flux Paths

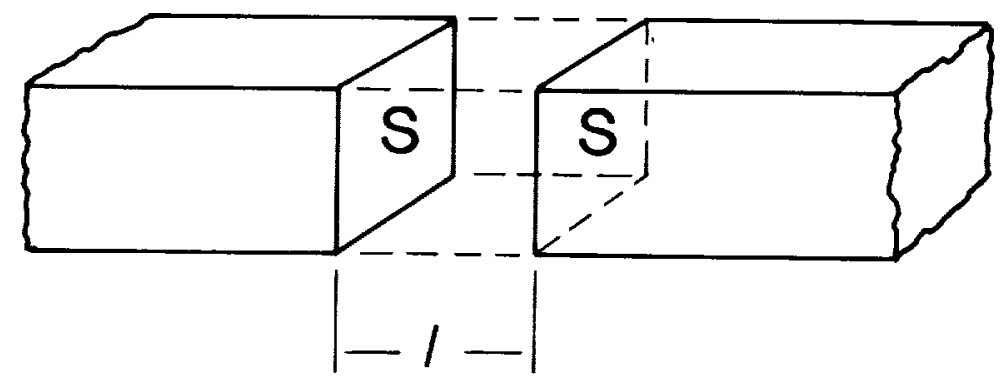

Figure 15. Parallel Plane Surfaces 


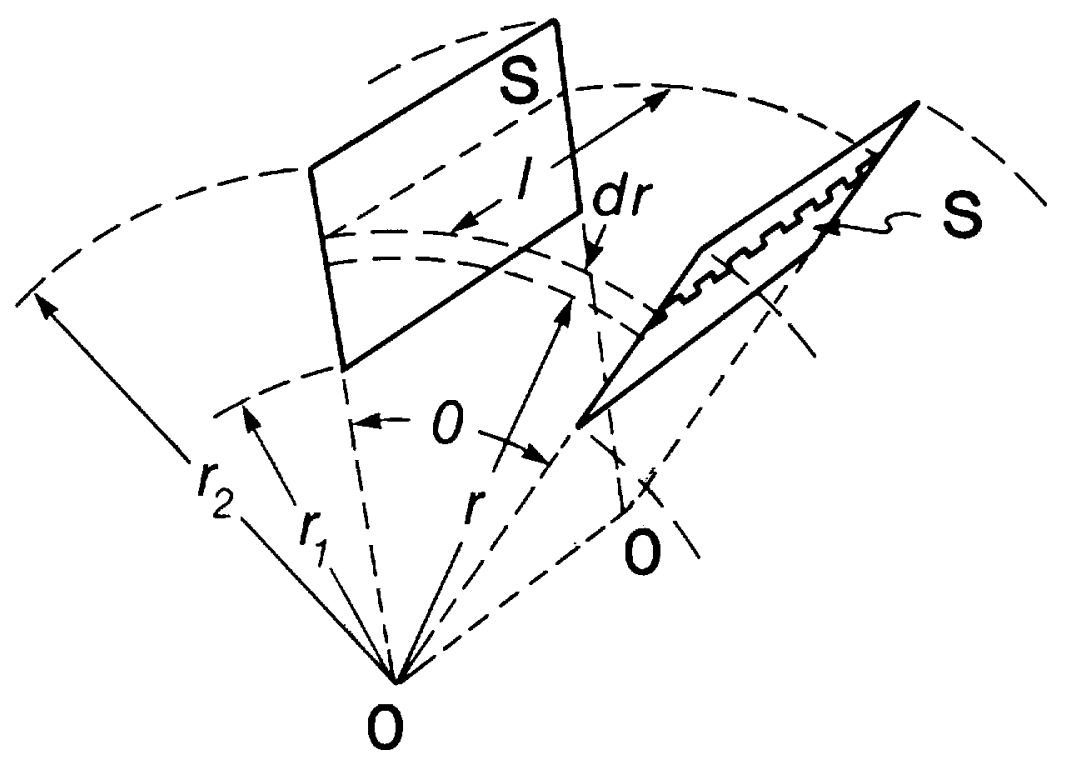

Figure 16. Non-parallel Plane Surfaces 
